\title{
Building an "eco-surplus culture" among urban consumers and restaurant settings for reducing wildlife trade
}

\author{
Minh-Hoang Nguyen \\ Ritsumeikan Asia Pacific University \\ Beppu, Oita 874-8577, Japan
}

August 10, 2021

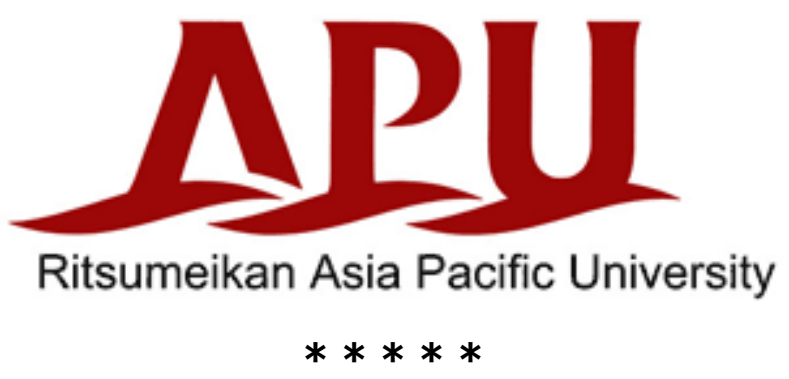

In the tropics, biodiversity loss is largely driven by the wildlife trade [1]. Vietnam is one of the South-East Asian countries actively involved in the international wildlife trading network, so poaching is widespread in Vietnam [2]. The government has implemented many laws, strategies and campaigns to tackle the wildmeat supply. Still, the endeavors remain ineffective due to the lack of resources for law enforcement and expanding organized criminal networks and corruption $[3,4]$. Meanwhile, reducing wildmeat consumption demand through raising awareness is being paid more attention by policymakers and conservationists [5].

However, raising awareness is not enough, as it is only temporarily effective. What we should do is to build an "eco-surplus culture" not only among residents living nearby the forest but also among urban consumers and restaurant settings [6]. The socio-cultural factors are the primary causes of wildlife consumption demand: wildmeat is used as a medium to show prestige and obtain social leverage [7]. If we successfully change the core cultural values of urban consumers and restaurant owners, wildmeat consumption behaviors will be substantially alleviated.

In my opinion, the culture could be changed by modifying the cost-benefit judgement of urban consumers and restaurant owners [8-10]. First, making them realize the adverse impacts of biodiversity loss induced by wildmeat consumption is vital. The target can be achieved through persistent social awareness-raising campaigns and educational programs [7]. Usually, enforcement of wildlife trade control is performed in rural areas and shows ineffective as poaching is directly related to the local livelihood, which is one of the fundamental needs [3]. Nonetheless, wildmeat consumption in urban areas is 
mainly motivated by cultural factors, which are not fundamental elements and can be substituted by other mediums rather than wildmeat. Therefore, legislation and law enforcement in urban areas are necessary to increase the urban consumers' and business owners' perceived cost and risk of consuming wildmeat. The perceived cost and risk might be associated with stringent monitoring, management, and sanctions at eateries (e.g. restaurants) and food providers.

As wildmeat consumption cultures have long been impeded in the Vietnamese lifestyle and habits, changing them is challenging. Nevertheless, reintroducing extinct animals and revising the biodiversity level are much more challenging or even impossible. Serious actions should be taken!

\section{References}

1. Milner-Gulland EJ, Bennett EL. (2003). Wild meat: the bigger picture. Trends in Ecology and Evolution, 18(7), 351-357.

2. Nuwer RL. (2018). Poached: Inside the dark world of wildlife trafficking. New York: Da Capo Press.

3. Challender DW, MacMillan DC. (2014). Poaching is more than an enforcement problem. Conservation Letters, 75$)$, 484-494.

4. Van Song N. (2008). Wildlife trading in Vietnam: situation, causes, and solutions. The Journal of Environment and Development, 17(2), 145-165.

5. Shairp R, Veríssimo D, Fraser I, Challender D, MacMillan D. (2016). Understanding urban demand for wild meat in Vietnam: implications for conservation actions. PLOS ONE, 11(1), e0134787.

6. Vuong $\mathrm{QH}$. (2021). The semiconducting principle of monetary and environmental values exchange. Economics and Business Letters, 10(3), 284-290.

7. Drury R. (2011). Hungry for success: urban consumer demand for wild animal products in Vietnam. Conservation and Society, 9(3), 247-257.

8. Vuong QH, Napier NK. (2015). Acculturation and global mindsponge: an emerging market perspective. International Journal of Intercultural Relations, 49, 354-367.

9. Vuong $\mathrm{QH}$, Nguyen $\mathrm{MH}$, Le TT. (2021). A mindsponge-based investigation into the psycho-religious mechanism behind suicide attacks. Warsaw, Poland: De Gruyter.

10. Nguyen MH, Le TT, Ho MT, Nguyen HTT, Vuong QH. (2021). Alice in Suicideland: Exploring the Suicidal Ideation Mechanism through the Sense of Connectedness and Help-Seeking Behaviors. International Journal of Environmental Research and Public Health, 18(7), 3681. 